\title{
Recognition and Status of Practicing Technological Competency as Caring in Nursing by Nurses in ICU
} Kaori Kato ${ }^{1}$, Misao Miyagawa $^{2}$, Yuko Yasuhara
Rozzano Locsin ${ }^{3}$ and Waraporn Kongswan

${ }^{1}$ TAOKA Mental Health Center, Tokushima, Japan

${ }^{2}$ Department of Nursing, Faculty of Health and Welfare, Tokushima Bunri University, Tokushima, Japan

${ }^{3}$ Department of Nursing, Institute of Biomedical Sciences, Tokushima University Graduate School, Tokushima, Japan

${ }^{4}$ Department of Nursing, Mifune Hospital, Kagawa, Japan

${ }^{5}$ Adult and Elderly Nursing Department, Faculty of Nursing, Prince of Songkla University, Songkhla, Thailand

\section{Abstract}

Aim: The purpose of this study was to survey how nurses who work in Intensive Care Units in Japan, realize and practice nursing based on the theory of Technological Competency of Caring in Nursing (TCCN).

Methods: The survey was conducted from September 2016 to November 2016 by questionnaire entitled, "Perceived Inventory of Technological Competency as Caring in Nursing (PITCCN)." It was developed based on Locsin's middle range theory on Technological Competency as Caring in Nursing. Copies of the Inventory were sent by mail to 426 ICU nurses working in hospitals within Japan. Three hundred eight questionnaire copies without missing values were returned (response rate was $72 \%$ ).

Results: (1) The scores about the practice situations of TCCN were significantly lower than those concerning the recognition of TCCN. Although ICU nurses recognized the need for TCCN, they thought that they had not practiced it enough. (2) In comparing the group having the education about caring and the group without the education, the scores concerning recognition of TCCN was significantly higher in educated group. However, no significant difference was found in the practice situation. (3) In comparing the variables "experience years of clinical nursing," although this did not have a significant difference in the variable "recognition of TCCN." However, the scores of the practice situation of TCCN was significantly higher compared between the group with 10 or more years of clinical experience than the group with less than 10 years' experience. (4) In comparing years of experience, ICU nurses' the scores concerning recognition of TCCN who had practice experience of 10 or more years was significantly higher than the group having less than fiveyears' experience.

Conclusion: By measuring nurses' practical situation of TCCN, this focus will be to deliver high quality nursing through continuing professional education.

\section{Introduction}

Caring is a core concept of nursing practice and nursing science [1,2]. Since Mayeroff (1990), a philosopher, declared his philosophical viewpoint on what is caring in his book On Caring, the term 'caring' has attracted attention within the discipline of nursing [3]. Theoretical development concerning caring in nursing advanced and became popular, although primarily in the United States. Nurse theorists including Watson (1979), Ray (1988), Boykin and Schoenhofer (2001), and Locsin (2005) [4] have grounded their theories on caring science in nursing.

Locsin (2005) [5] described nursing as technological competency as caring in nursing focused on the proficient practice of nurses using technologies to know persons as caring while affirming that being technologically competent is being caring. The general theory of Nursing as Caring by Boykin and Schoenhofer (2001) is the basis of Locsin's theory [6]. Emphasized that it is important for nurses to recognize and realize persons as constantly growing in their caring, Locsin further stressed that knowing persons through technologies requires proficiency and knowledgeable practice.

Since the 1990s, the practice of nursing in Japan that was grounded in caring shifted from a treatment-centered care to one that is patient care-centered [7]. Research exists about the method of caring based upon the values of nurses in clinical practice [8]. Nurses entering the workforce are faced with many challenges, but today the multiple demands of patient care are complicated by the nurse's need to keep abreast with the fast-changing and advancing technologies[9]. Therefore, with new developments in health care and technology, it is important for nurses to be technologically competent and have the abilities to maintain a caring-healing environment.

Instrument that measures caring in nursing, specifically the expression of technological competency as caring is Technological Competency as Caring in Nursing Instrument (TCCNI) [10,11]. In reviewing the literature, a study was found based on Locsin's theory that surveyed nurses' recognition of Technological Competency as Caring in Nursing (TCCN). The result showed that nurses' recognition

"Corresponding Author: Prof. Tetsuya Tanioka, Department of Nursing, Institute of Biomedical Sciences, Tokushima University Graduate School, Tokushima, Japan; E-mail: tanioka.tetsuya@tokushima-u.ac.jp

Citation: Kato K, Miyagawa M, Yasuhara Y, Osaka K, Kataoka M, et al. (2017) Department of Nursing, Institute of Biomedical Sciences, Tokushima University Graduate School, Tokushima, 770-8501, Japan. Int J Nurs Clin Pract 4: 264. doi: https://doi.org/10.15344/2394-4978/2017/264

Copyright: () 2017 Kato et al. This is an open-access article distributed under the terms of the Creative Commons Attribution License, which permits unrestricted use, distribution, and reproduction in any medium, provided the original author and source are credited. 
Citation: Kato K, Miyagawa M, Yasuhara Y, Osaka K, Kataoka M, et al. (2017) Department of Nursing, Institute of Biomedical Sciences, Tokushima University Graduate School, Tokushima, 770-8501, Japan. Int J Nurs Clin Pract 4: 264. doi: https://doi.org/10.15344/2394-4978/2017/264

Page 2 of 8

regarding TCCN was high. Furthermore, nurses' self-awareness was significantly but moderately correlated with nurses' recognition regarding TCCN [12]. However, little is known about the recognition and practice situation about the use of the TCCN in intensive care units (ICU)

The purpose of this study was to survey how nurses who work in ICUs in Japan, realize and practice nursing based on the theory of TCCN.

\section{Method}

\section{Survey method}

The data collection period was from September 2016 to November 2016. Forty-three hospitals were carefully selected out of the 404 general hospitals in Japan. Selection criteria was focused on hospital ward functions for which specific intensive care management fees or critical care medicine fees were additionally charged. Hospital administrators were requested to cooperate by telephone and to distribute questionnaire survey copies to ICU nurses who were working in their ICUs. Of these hospitals, 17 accepted the invitation to either mail the questionnaire copies or promote the web-based questionnaire delivery system by Survey Monkey ${ }^{\circ}$ ). Copies of the PITCCN were sent to 426 ICU nurses working in hospitals. However, only 308 questionnaire copies were returned that did not have any missing values (response rate was $72 \%$ ).

\section{Scales on recognition and practice situation of technological} competency as caring in nursing

This survey used the "Perceived Inventory of Technological Competency as Caring in Nursing (PITCCN) [13] instrument which was developed based on Locsin's middle range theory [5]. The PITCCN has four factors labelled as (1) Training of nurses to provide optimal care, (2) Empirical knowledge and knowing the whole person, (3) Utilization of information obtained from technology and continuously knowing, and (4) Intentional and ethical nursing of persons.

Cronbach's alpha was 0.894 for the questionnaire (20 items) and $0.869,0.872,0.876$, and 0.734 , for the four factors, respectively. The PITCCN showed that the overall data obtained high internal consistency for each factor. The Likert-scale was used for scaling responses of questionnaires (From 1 strongly disagree to 5 strongly agree). The following negatively worded items were inversely scored: item numbers Q12, Q13, Q14, Q15, and Q22.

\section{Definitions of terms used in this study}

Recognition of TCCN is the ICU nurses' agreement of technological competency as caring in nursing based on Locsin's theory, as measured by the PITCCN. Higher score means higher recognition of TCCN.

Practical situation of TCCN is the viewpoint of ICU nurses regarding their real practice of technological competency as caring in nursing based on Locsin's theory as measured by evaluation of selfusing PITCCN. Higher score means higher practice of TCCN.

\section{Analysis method}

The differences between the 'recognition of TCCN' based on attributes and its practice situations were analyzed using the Welch's t-test comparing the two groups, and Welch's one-way analysis of variance was also used for comparing between the three groups. Dunnett's T3-test was used for multiple comparisons.

The participants were classified into two groups, those having and not having the experience of receiving education on caring. Further classification included those having the experience-into three groups: those "less than five years", "five years and less than 10 years" and "10 years or more".

For the analysis of differences between the recognition and practical situation of TCCN by each of four factors, Mean Factor Points (MFP) of items of each factor were calculated and compared. The MFP derived from the total score factor and divided by number of items was calculated including the standard deviation, range, and Confidence Interval (CI) at 95\%. Statistical significance was set at 0.05 level. All statistical analyses were performed using the SPSS for Windows software (version 20.0; SPSS Inc., Chicago, IL).

\section{Ethical considerations}

The University of Tokushima Hospital Clinical Study Ethical Review Board approved this research study (approval No. 2585). Return of the survey implied that the subjects gave consent to participate in the study, who were notified that privacy would be protected.

\section{Results}

\section{Demographic characteristics}

The questionnaire was sent to 426 nurses; of which only 326 valid responses were returned and received. The analysis was conducted with 308 responses excluding the ones with one or more missing value data on the PITCCN items (response rate was $72 \%$ ).

There were 45 males (14.6\%), 261 females (84.7\%). As for the experience in years of clinical nursing, there were 72 (23.4\%) who have less than five years' experience, $90(29.2 \%)$ who have five to less than 10 years' experience, and $146(47.4 \%)$ who have 10 years or more. As for the experience in years of ICU nursing, there were 193 (62.7\%) who have less than five years' experience, $82(26.6 \%)$ who have five to less than 10 years' experience, and $30(9.7 \%)$ who have 10 years or more.

Those who had received education on caring were 56 (18.2\%) participants, while $250(81.2 \%)$ did not receive education on caring. As for their academic background, there were 223 (72.4\%) graduates from vocational collages, that of four-year colleges was 39 (12.7\%), that of vocational coursesin high school was $20(6.5 \%)$, that of junior colleges was 17 (5.5\%), and with master's degrees $1(0.3 \%)$.

\section{Results of comparison between technological competency as caring in nursing "recognition" and its "practice situation"}

In all factors, MFPs of recognition of TCCN were significantly higher than the practical situations $(\mathrm{p}<0.001)$. In addition, in all low-order items, the number of respondents who answered, "strongly agree" were more on recognition of TCCN than on the practice situations. 
Citation: Kato K, Miyagawa M, Yasuhara Y, Osaka K, Kataoka M, et al. (2017) Department of Nursing, Institute of Biomedical Sciences, Tokushima University Graduate School, Tokushima, 770-8501, Japan. Int J Nurs Clin Pract 4: 264. doi: https://doi.org/10.15344/2394-4978/2017/264

The item in which $95 \%$ of $\mathrm{CI}$ was low in recognition it was "Q1: Nurses should assess patient's condition from information acquired using technology" (3.83-4.03) in the low-order items of Factor 3 (Utilization of information obtained from technology and continuous knowing).

On the other hand, there were the items in which $95 \%$ CI was low in practical situations in the low-order items of Factor 2 (Empirical knowledge and whole human knowing): "Q4: Nurses should be knowledgeable of anatomy and physiology (2.93-3.13)", "Q5: Nurses should be knowledgeable of clinical pharmacology" (2.64-2.84), and "Q6: Nurses should be well-versed in the state-of-the-art of medical devices in their department (2.88-3.07)".

\section{Comparative results (total scores) on "recognition of TCCN and its practice situation" by attributes of subjects}

The recognition of TCCN was significantly higher in the group having received education on caring than the group who did not have any $(\mathrm{p}<0.01)$. No significant difference was observed based on the experienced years of clinical nursing. As for the experience in ICU, it was significantly higher in the group having 10 or more years' of experience than the group having less than five years' experience ( $\mathrm{p}$ $<0.05)$.

The practice situation of TCCN did not significantly differ whether nurses received education on caring or not. As for the experience in years of clinical nursing, the scores revealed significantly higher in the group having 10 or more years' of experience than the group having less than five years' experience $(\mathrm{p}<0.05)$, and the group have five to less than 10 years' experience $(\mathrm{p}<0.05)$. As for the experience in years of ICU nursing, the scores were significantly higher in the group having 10 or more years' experience than the group having less than five years' experience $(\mathrm{p}<0.001)$, and the group have five to less than 10 years' experience $(\mathrm{p}<0.05)$.

\section{The comparison of scores for the recognition and practice situation of TCCN by each attribute and factors}

The comparative scores for the recognition and practice situation of TCCN for each attribute and factor is shown in Table 4. The recognition of TCCN was significantly higher in the group having received education on caring than the group that did notreceive education on caring in [Factor 2: Empirical knowledge and knowing the whole person $(\mathrm{p}<0.001)]$ and [Factor 4: Intentional and ethical nursing of persons $(p<0.001)]$. However, no significant difference was showed in [Factor 1: Training of nurses to provide optimal care] and [Factor 3: Utilization of information obtained from technology and continuous knowing].No significant difference of TCCN was observed in all factors in the practical situation.

No significant difference in the recognition of TCCN was observed in all factors based on the comparison of the experience in years of clinical nursing. The practice situations of TCCN was significantly higher in the group having 10 or more years' experience than the group having less than five years' experience in Factor $1(\mathrm{p}<0.05)$, Factor $2(\mathrm{p}<0.05)$ and Factor $3(\mathrm{p}<0.01)$. It was significantly higher in the group having 10 or more years' experience than the group having five to less than 10 years' experience in Factor $4(\mathrm{p}<0.05)$. Also, it was significantly higher in the group having 10 or more years nursing experience than less than five years nursing experience in other factors [Factor 1 and $2(\mathrm{p}<0.05)$, Factor $3(\mathrm{p}<0.01)]$.
No significant difference in the recognition of TCCN was observed in Factor 1 by comparing experience in years in ICU. It was significantly higher in the group having 10 or more years' experience than the group having less than five years' experience in Factor 2 (p $<0.01$ ). It was significantly higher in the group having five to less than 10 years' experience than the group having less than five years' experience in Factor $3(\mathrm{p}<0.05)$ and Factor $4(\mathrm{p}<0.05)$.

The practice situation of TCCN was significantly higher in the group having 10 or more experience in ICU than the group having less than five years' experience in all factors: Factor $1(\mathrm{p}<0.01)$, Factor $2(\mathrm{p}<0.05)$, Factor $3(\mathrm{p}<0.001)$, and Factor $4(\mathrm{p}<0.05)$.

\section{Discussion}

As the result of the comparison of scores for the recognition and practice situation of TCCN by factor, the scores for recognition were significantly higher than the scores of the practice situations in all four factors.

It was recognized that although they knew the importance of the TCCN, the nurses in the ICU considered that they had not practiced being technologically competent as expression of caring enough when they did the self-evaluation about their practical situation. Although they scored more than four points in $95 \% \mathrm{CI}$ regarding the necessity of knowledge of anatomy, physiology, clinical pharmacology and the newest medical instruments available in their department, as regards the recognition, the nurses only gained three points in their evaluation

\begin{tabular}{|c|c|c|}
\hline & & $\mathrm{n}=308$ \\
\hline \multicolumn{2}{|c|}{ Demographic characteristics } & $\mathrm{n}(\%)$ \\
\hline \multirow[t]{3}{*}{ Gender } & Male & $45(14.6 \%)$ \\
\hline & Female & $261(84.7 \%)$ \\
\hline & No response & $2(0.6 \%)$ \\
\hline \multirow{3}{*}{$\begin{array}{l}\text { Experience years of } \\
\text { clinical Nursing }\end{array}$} & Less than 5 years & $72(23.4 \%)$ \\
\hline & 5 less than 10 years & $90(29.2 \%)$ \\
\hline & 10 years more & $146(47.4 \%)$ \\
\hline \multirow{4}{*}{$\begin{array}{l}\text { Experience years of ICU } \\
\text { Nursing }\end{array}$} & Less than 5 years & $193(62.7 \%)$ \\
\hline & 5 less than 10 years & $82(26.6 \%)$ \\
\hline & 10 years more & $30(9.7 \%)$ \\
\hline & No response & $3(0.9 \%)$ \\
\hline \multirow{3}{*}{$\begin{array}{l}\text { Existence of experiance } \\
\text { receiving education on } \\
\text { caring }\end{array}$} & Yes & $56(18.2 \%)$ \\
\hline & No & $250(81.2 \%)$ \\
\hline & No response & $2(0.6 \%)$ \\
\hline \multirow[t]{8}{*}{ Education Levels } & Nursing school & $223(72.4 \%)$ \\
\hline & University (Nursing) & $39(12.7 \%)$ \\
\hline & $\begin{array}{l}\text { High School Advanced } \\
\text { Course (Nursing) }\end{array}$ & $20(6.5 \%)$ \\
\hline & Junior College (Nursing) & $17(5.5 \%)$ \\
\hline & M.S & $1(0.3 \%)$ \\
\hline & Ph. D. & $0(0 \%)$ \\
\hline & Others & $3(1.0 \%)$ \\
\hline & No response & $5(1.6 \%)$ \\
\hline $\begin{array}{l}\text { Table 1: Demographic dat } \\
\text { ICU: Intensive Care Unit. }\end{array}$ & & \\
\hline
\end{tabular}

Int J Nurs Clin Pract

ISSN: 2394-4978

IJNCP, an open access journal

Volume 4. 2017. 264 
Citation: Kato K, Miyagawa M, Yasuhara Y, Osaka K, Kataoka M, et al. (2017) Department of Nursing, Institute of Biomedical Sciences, Tokushima University Graduate School, Tokushima, 770-8501, Japan. Int J Nurs Clin Pract 4: 264. doi: https://doi.org/10.15344/2394-4978/2017/264

Page 4 of 8

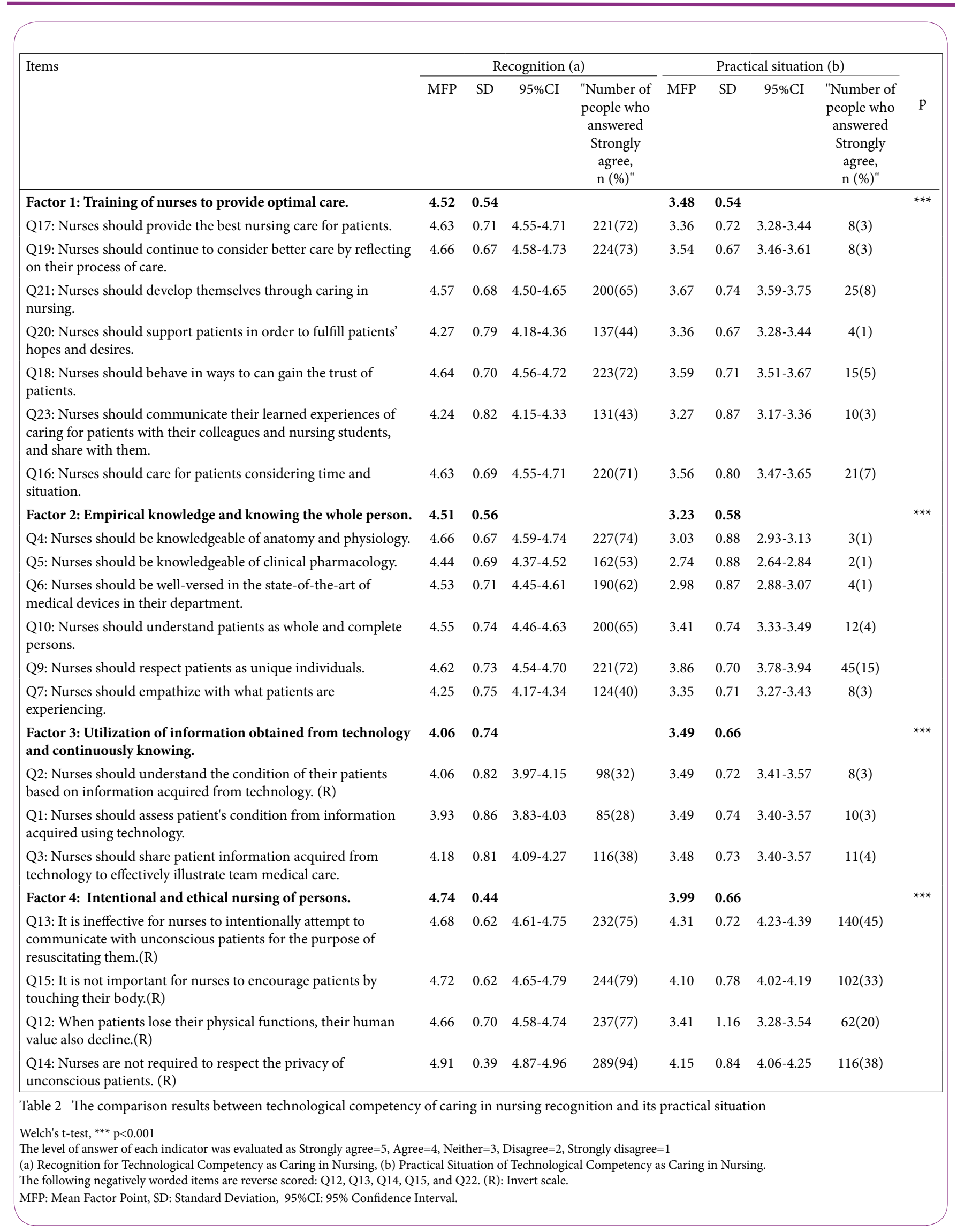


Citation: Kato K, Miyagawa M, Yasuhara Y, Osaka K, Kataoka M, et al. (2017) Department of Nursing, Institute of Biomedical Sciences, Tokushima University Graduate School, Tokushima, 770-8501, Japan. Int J Nurs Clin Pract 4: 264. doi: https://doi.org/10.15344/2394-4978/2017/264

Page 5 of 8

\begin{tabular}{|c|c|c|c|c|c|c|}
\hline & \multicolumn{6}{|c|}{ Total scores } \\
\hline & $\mathrm{n}$ & Mean & $\mathrm{SD}$ & $95 \% \mathrm{CI}$ & $\mathrm{p}$ & * \\
\hline \multicolumn{7}{|c|}{ Recognition for technological competency of caring in nursing. } \\
\hline \multicolumn{7}{|c|}{ Existence of experience receiving education on caring ${ }^{1)}$} \\
\hline Yes & 56 & 91.98 & 5.87 & $90.41-93.55$ & $* *$ & \\
\hline No & 250 & 89.38 & 8.66 & $88.30-90.46$ & & \\
\hline \multicolumn{7}{|c|}{ Experience years of clinical Nursing ${ }^{2)}$} \\
\hline a) Less than 5 years & 72 & 90.14 & 8.69 & $88.10-92.18$ & NS & \\
\hline b) 5 -less than 10 years & 90 & 89.81 & 6.61 & $88.43-91.20$ & & \\
\hline c) 10 years or more & 146 & 89.72 & 8.95 & $88.26-91.18$ & & \\
\hline \multicolumn{7}{|c|}{ Experience years of ICU Nursing ${ }^{2)}$} \\
\hline a) Less than 5 years & 193 & 88.81 & 8.86 & $87.55-90.07$ & * & ${ }^{*} \mathrm{a}<\mathrm{c}$ \\
\hline b) 5-less than 10 years & 82 & 91.24 & 7.26 & $89.65-92.84$ & & \\
\hline c) 10 years or more & 30 & 91.97 & 5.40 & $89.95-93.98$ & & \\
\hline \multicolumn{7}{|c|}{ Practical situation on technological competency of caring in nursing. } \\
\hline \multicolumn{7}{|c|}{ Existence of experience receiving education on caring ${ }^{1)}$} \\
\hline Yes & 56 & 71.48 & 9.61 & $68.91-74.06$ & NS & \\
\hline No & 250 & 69.90 & 9.53 & $68.71-71.08$ & & \\
\hline \multicolumn{7}{|c|}{ Experience years of clinical Nursing ${ }^{2)}$} \\
\hline a) Less than 5 years & 72 & 68.00 & 9.99 & $65.65-70.35$ & $* *$ & $\begin{array}{l}{ }^{*} \mathrm{a}<\mathrm{c} \\
{ }^{*} \mathrm{~b}<\mathrm{c} "\end{array}$ \\
\hline b) 5-less than 10 years & 90 & 68.67 & 8.93 & $66.80-70.54$ & & \\
\hline c) 10 years or more & 146 & 72.12 & 9.39 & $70.58-73.65$ & & \\
\hline \multicolumn{7}{|c|}{ Experience years of ICU Nursing ${ }^{2)}$} \\
\hline a) Less than 5 years & 193 & 68.77 & 9.02 & $67.49-70.05$ & $* * *$ & $\begin{array}{c}" * * * a<c \\
{ }^{*} b<c "\end{array}$ \\
\hline b) 5-less than 10 years & 82 & 71.12 & 10.35 & $68.85-73.40$ & & \\
\hline c) 10 years or more & 30 & 76.00 & 8.72 & $72.74-79.26$ & & \\
\hline
\end{tabular}

of practice situations. From this result, it is possible that although they strongly recognize the necessity of knowledge acquisition, many nurses consider that they do not have enough knowledge to work in ICU.

Recently, medical procedures and medical instruments were advanced, and the newest ones were introduced in succession at high-level medical sites such as ICUs [14]. This acquisition required thorough knowledge for them.

It is well-known that nurses who are working in environments like an ICU, have high professional consciousness, seeking greater knowledge and technological know-how [15]. Experienced critical care nurses are able to transcend the obtrusive nature of technology and deliver expert care to their patients. However, the journey to proficiency in technology is very demanding and novice nurses have difficulty realizing caring in their technological competency [16]. With nurses having less than five years being included in this research may be the variable cause for the low evaluation of practice situation.
According to the total TCCN scores, the recognition of TCCN was higher in the group having received education on caring than the group that did not receive the education. Meanwhile, no significant differences in practice situations on TCCN were observed between the groups having received education on caring and the groups who have not received the education. Recognition of TCCN was significantly higher in [Factor 2] and [Factor 4] in the group having received education on caring than the group having not. "Holistic approach" and "intentional involvement" constituting Factor 2 and Factor 4 , respectively, are emphasized as the central ideas of the theory of caring in the nursing field.

Boykin and Schoenhofer (2001) [6] argued that it is important to know and understand persons from the empirical, personal, ethical and aesthetic [17] vantage points based on the premise that "humans are always whole and complete in the moment." It was presumed that the group that received education on caring was highly conscious of care based on the caring practice that they so far learned. Meanwhile, considering that no difference was observed in practice situations, it is possible that changes in the 'recognition' through education have 
Citation: Kato K, Miyagawa M, Yasuhara Y, Osaka K, Kataoka M, et al. (2017) Department of Nursing, Institute of Biomedical Sciences, Tokushima University Graduate School, Tokushima, 770-8501, Japan. Int J Nurs Clin Pract 4: 264. doi: https://doi.org/10.15344/2394-4978/2017/264

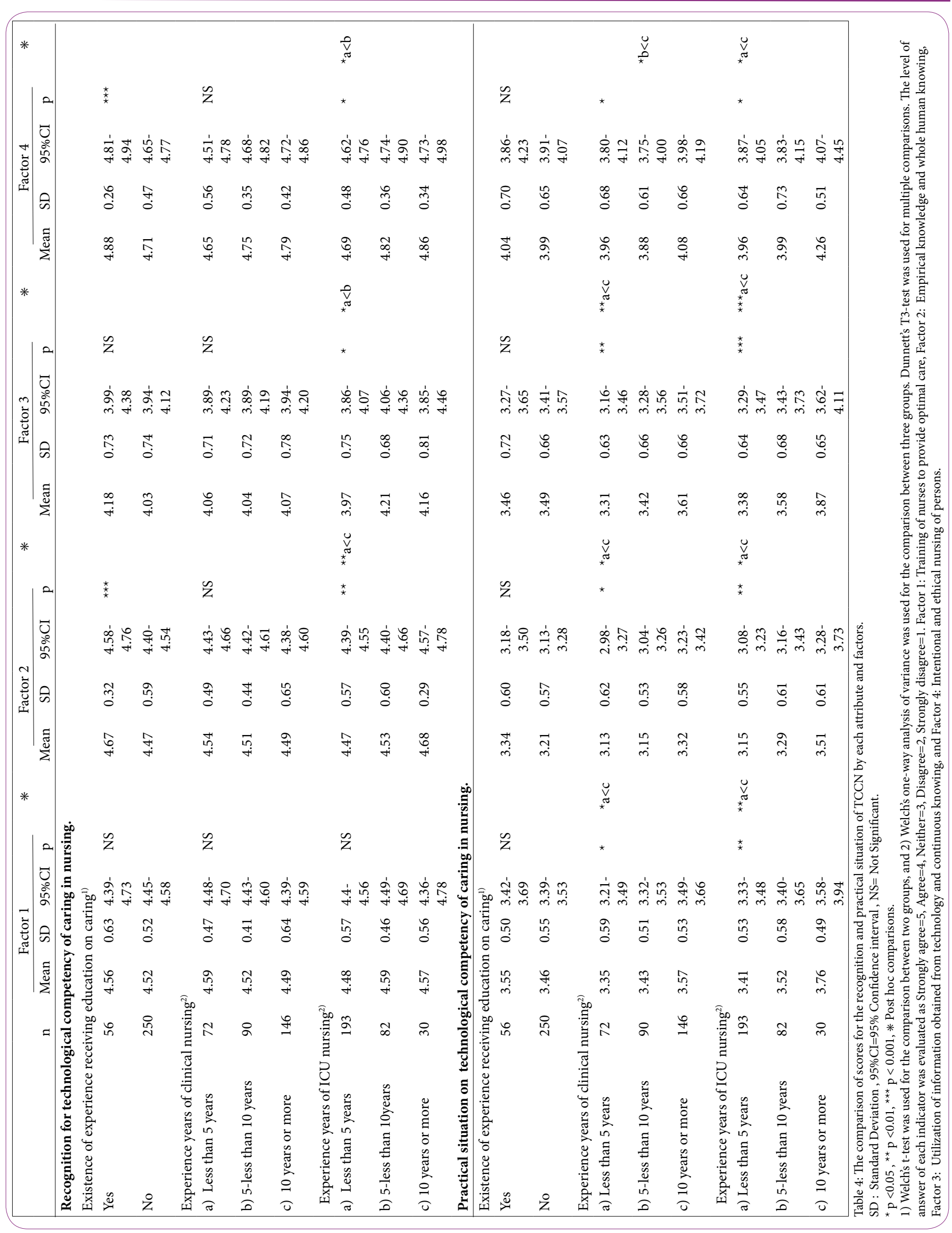


Citation: Kato K, Miyagawa M, Yasuhara Y, Osaka K, Kataoka M, et al. (2017) Department of Nursing, Institute of Biomedical Sciences, Tokushima University Graduate School, Tokushima, 770-8501, Japan. Int J Nurs Clin Pract 4: 264. doi: https://doi.org/10.15344/2394-4978/2017/264

Page 7 of 8

occurred. However, it was presumed that the reason recognition was high, but not observed significantly different in practice situations was that the experience as a nurse and experience in the ICU of the group having received education was quite short (10 years or more).

No significant difference was observed in the recognition of TCCN based on the years of nursing experience. Meanwhile the recognition of TCCN of the group having 10 or more years' experience in the ICU was significantly higher than that of the group having less than five years' experience. It can be argued that practical experience in the ICU has a greater contribution to the recognition of TCCN than experience as a general practice nurse.

The study in Nepal, Mizuno and others found a significant difference in the nurses' recognition of their caring behaviors based on the level of their working experience [18]. However, Kongsuwan and Matchim reported that the length of working experience was not correlated significantly with ICU nurses' agreement on TCCN [12].

Boykin and Schoenhofer (2001) [6] expressed that all nursing knowledge resides in "nursing situations" where the nurse and the one who is nursed share lived experiences. It was presumed that the technical competency as caring in nursing was acquired in the practical way as the nursing in ICU.

Comparing by each factor, it was significantly higher in the group having 10 or more years' experience than the group having less than five years' experience in Factor 2, and it was significantly higher in the group having five to less than 10 years' experience than the group having less than five years' experience in Factor 3 and 4.

Significant differences appeared based on the years of experience in ICU, not by the years of nursing experience. It is understood that the nurses working in an ICU have practice techniques specific to the ICU setting. The total scores of practice situations in the group having 10 or more years nursing experience was significantly higher than that of the group having less than 10 years' experience. The total scores and the scores of all four factors acquired by the group having 10 or more years' experience in the ICU were significantly higher than those of the group having less than five years' experience.

Benner [19] described the acquisition of nursing expertise and proposed five possible expertise levels, namely, novice, advanced beginner, competent, proficient, and expert. Competent nurses are task-oriented and deliberately structure their work in terms of plans for goal achievement. Proficient nurses perceive situations as a whole and have more ability to recognize and respond to changing circumstances. Moreover, Benner [20] described that "skilled knowhow" includes situated judgment, reasoning across time about the particular and taking appropriate actions in response to the patient's condition and responses to therapies. Also, she [21] mentioned that technology has made lifesaving critical care possible and accessible to most people. Technology can facilitate or disrupt effective order and functioning, or it can shore up disorder and breakdown. It takes good clinical judgment to decide when it is doing what. In addition, the skills of meeting the critically ill patient call for extraordinary attentiveness, attunement, and respect [22].

From the above, it was considered that proficiency of caring in the ICU is important for practice based on TCCN. By measuring nurses' practical situation of TCCN, it provides patient care evaluation. This focus will be to deliver high quality nursing through continuing professional education.

\section{Limitation}

Because the respondents to this survey were not random selected, the results cannot be generalized. Furthermore, nurses with short experiences in the ICU were included. In order to clarify TCCN of nurses working in an ICU, in future studies, it is necessary to study the phenomenon with nurses who have worked in an ICU for a longer time period.

\section{Conclusions}

The recognition and the practice situation of TCCN of nurses working in ICUs in Japan were surveyed, and the findings are as follows: (1) The scores reflective of practice situations of TCCN were significantly lower than those on the recognition of TCCN. It was assumed that although ICU nurses recognized the need for TCCN, they admitted that they had not practiced it enough. (2) In comparing the group having the education about caring and the group without the education, the scores concerning recognition of TCCN was significantly higher in educated group. However, no significant difference was found in the practice situation. (3) In comparing the variables "experience years of clinical nursing," although this did not have a significant difference in the variable "recognition of TCCN". However, the scores of the practice situation of TCCN was significantly higher compared between the group with 10 or more years of clinical experience than the group with less than 10 years' experience. (4) In the comparison based on years of experience in the ICU, the practical situation was significantly higher in the group having 10 or more years' experience than in the group having less than five years' experience.

\section{Competing Interests}

The author declears that they have no competing interest exists.

\section{Author Contributions}

Kaori Kato, Tetsuya Tanioka were responsible for the Study design and manuscript preparation. Kaori Kato was responsible for data collection. Misao Miyagawa, Yuko Yasuhara, Kyoko Osaka, Mutsuko Kataoka, Hirokazu Ito, Rozzano Locsin and Waraporn Kongswan were responsible for analysis of data and discussion of findings.

\section{Acknowledgement}

We would like to express our deep gratitude to the Japanese nurses and nursing administrators who participated in this study.

\section{Funding}

This work was supported by JSPS KAKENHI Grant, Number $15 \mathrm{~K} 15798$

\section{References}

1. Barry C, Gordon S, King B (2015) Nursing Case Studies in Caring Across the Practice Spectrum. (1st edition), New York: Springer Pub Co., USA, p.203.

2. Swanson KM (1991) Empirical development of a middle range theory of caring. Nurs Res 40: 161-166. 
Citation: Kato K, Miyagawa M, Yasuhara Y, Osaka K, Kataoka M, et al. (2017) Department of Nursing, Institute of Biomedical Sciences, Tokushima University Graduate School, Tokushima, 770-8501, Japan. Int J Nurs Clin Pract 4: 264. doi: https://doi.org/10.15344/2394-4978/2017/264

3. Smith MC (2012) Caring and the Discipline of Nursing: Caring in Nursing Classics. (1st edition), New York: Springer Pub Co., USA, pp.535.

4. Smith M, Parker ME (2014) Nursing Theories and Nursing Practice. (4th Edition), New York: F. A. Davis Company, USA, 576 p.

5. Locsin RC (2005) Technological Competency as Caring in Nursing: A Mode for Practice. (1st edition), Indianapolis: Sigma Theta Tau International Honor Society of Nursing Press, USA, $229 \mathrm{p}$

6. Boykin A, Schoenhofer S (2001) Nursing as caring: A model for transforming practice. (2nd edition), Burlington: Jones \& Bartlett Learning, USA, 71 p.

7. Ministry of Health, Labour and Welfare (2007) Annual Report on Health.

8. Gregg MF, Magilvy JK (2004) Values in clinical nursing practice and caring Japan Journal of Nursing Science 1: 11-18.

9. Crocker C, Timmons S (2009) The role of technology in critical care nursing J Adv Nurs 65: 52-61.

10. Locsin RC (1999) Development of an instrument to measure technological caring in nursing. Nursing and Health Sciences 1: 27-34.

11. Parcells DA, Locsin RC (2011) Development and psychometric testing of the technological competence as caring in nursing instrument. International Journal for Human Caring 15: 8-13.

12. Biswas SR, Kongsuwan W, Matchim Y (2016) Technological competency as caring in nursing as perceived by ICU nurses in Bangladesh and its related factors. Songklanagarind Journal of Nursing 36: 1-20.

13. Kato K, Tanioka T, Yasuhara Y, Miyagawa M, Osaka K, et al. (2017) The Development of the Perceived Inventory of Technological Competency as Caring in Nursing. Shikoku Acta Medica 73: 151-160.

14. Locsin RC, Purnell M (2015) Advancing the Theory of Technological Competency as Caring in Nursing: The Universal Technological Domain. International Journal for Human Caring 19: 50-54.

15. Haghenbeck KT (2005) Critical care nurses' experiences when technology malfunctions. J N Y State Nurses Assoc 36: 13-19.

16. McGrath $M(2008)$ The challenges of caring in a technological environment: critical care nurses' experiences. J Clin Nurs 17: 1096-1104.

17. Carper BA (1978) Fundamental Patterns of Knowing in Nursing. Advances in Nursing Science 1: 13-24.

18. Mizuno M, Ozawa M, Evans DR, Okada A, Takeo K (2005) Caring behaviors perceived by nurses in a Japanese hospital. Journal of Nursing Studies 4: 1-7.

19. Benner P (1982) From novice to expert. Am J Nurs 82: 402-407.

20. Benner $P$ (2005) Extending the dialogue about classification systems and the work of professional nurses. Am J Crit Care14: 242-243.

21. Benner $P$ (2003) Beware of technological imperatives and commercial interests that prevent best practices! Am J Crit Care12: 469-471.

22. Benner $P$ (2002) Caring for the silent patient. Am J Crit Care11: 480-481. 